\title{
MARKETING RESEARCHES OF MARKET ON MEDICATIONS FOR NEUROPROTECTIVE ACTION IN UKRAINE
}

Abstract The assortment of neuroprotective medications, presented in the pharmaceutical market of Ukraine, has been investigated in this article. Correlation of medications of home and foreign manufacture within the limits of each pharmacotherapeutic group of medications was determined.

The analysis of the assortment of neuroprotective medications has also been conducted regarding dosage forms.

During the research of assortment of neuroprotective action medications, present in the market of Ukraine, we used data of the State Register of Medicinal Remedies of the Ministry of Health of Ukraine. While conducting marketing analysis of the market of medications, we adhered to the ATC classification system.

It was determined that home manufacturers supply the internal pharmaceutical market with $38.8 \%$ of preparations of the investigated group. Herewith, leading positions in terms of supply volume belong to ZAT (Close Joint-Stock Company), pharmaceutical firm "Darnytsia" and JSC "Galychpharm". Preparations of each of the above-mentioned firms make 10.7\% of the general assortment of home-produced medications.

The rating of 25 foreign countries - suppliers of medications for neuroprotective action to the pharmaceutical market of Ukraine showed that the leader in terms of volume of the presented medications is Russia, whose medications make $16.4 \%$ of the assortment of neuroprotective medications of foreign manufacture. The second place belongs to Germany (15\%), and India (11.6\%) takes the third place.

There was disclosed expediency of expansion of home-produced preparations nomenclature and their dosage forms for ischaemic stroke treatment.

Keywords

marketing research - neuroprotective medications - pharmaceutical market of Ukraine - assortment - ischaemic stroke

\section{Introduction}

Currently, cerebral strokes are one of the principal reasons of death rate and disability in the world [Lopez et al., 2006, Marunich et al., 2011]. Annually about 16 million people fall ill with cerebral stroke, and about 7 million die as a result of it. In Ukraine, about 110,000 cerebral strokes are being registered a year and about 40,000 end up being fatal.

The problem of stroke is acute not only for Ukraine but also for many European countries. Substantial differences in prevalence, morbidity and death rate from a stroke are marked among the countries of Eastern and Western Europe. As a rule, it is stipulated by the differences of risk factors, in particular by the level of arterial hypertonia, and also other risk factors which result in the greater amount of heavy strokes in Eastern Europe [Anishchenko et al., 2011, Brainin et al., 2000].

Strokes are the main reason of incapacitation, second reason by value of dementia and third by value of death after heart diseases and malignant tumours. It is stated that a stroke causes the death of about $30 \%$ of patients in the first month after the disease's nascence, repeated strokes arise with a frequency of $4-14 \%$ a year. In general, death rate during the first year reaches $30-40 \%$. More than in $50 \%$ of disease cases, evident residual physical disability of patients with functional disorder is specified.

Treatment of stroke, long-term disability and invalidisation result in considerable economic charges. In the conditions of hard deficit of money, which we observe in the Ukrainian system of health protection, the question of effective, economic and rational stroke treatment acquires an important social significance. Therefore, search of treatment methods allowing to decrease medical and social burden of ischaemic stroke is one of high priority directions of modern medicine and pharmacy. Restorative therapy gains an important value for functional recovery of brain dysfunction after one has suffered a stroke. Restorative therapy is aimed at flexibility increase of unaffected brain tissue and activation of polysynaptic interneuronic connections [Mureshanu, 2007]. Medicated neuroprotection is aimed to protect neurons at a focal ischaemia, prevent neuronal "death" at the cellular and molecular levels, correct the 
consequences of vascular disease, have the possibility of the maximum early use, reduce sharp strokes severity, reduce the volume of brain infarction, increase therapeutic window for implementation of thrombolysis and protect brain from secondary reperfusion injury [Alonso de Lecinana et al., 2005]. As mentioned above, the aim of our research is the analysis of the presented assortment of medications of neuroprotective action in the pharmaceutical market of Ukraine, which are used for ischaemic stroke treatment.

\section{Material and methodology}

We conducted the research of the medications assortment according to the data of the State Register of Medicinal Remedies of the Ministry of Health of Ukraine and ATC classification system. Preparations of neuroprotective action became the objective of our research (Fig. 1).

Herewith, the method of secondary marketing information analysis was used. Compendium of 2009 was used as the informative sources [Information retrieval system "State Register of drugs of Ukraine", Kovalenko and Viktorova, 2009]. During the research, we used statistical, logical and graphical methods.

\section{Results}

\section{Nomenclature of neuroprotective medications}

The study of nomenclature of the neuroprotective medications presented in home pharmaceutical market became the first stage of the research. It is determined that as of January 2013, the assortment of the medications registered in Ukraine was presented by 338 preparations of neuroprotective action (211 trade names aside from producer). Among them, the most part of medications in the home pharmaceutical market was presented by preparations of group N06B X - other psychostimulants and nootropics (32\%), N07C A - anti-vertigo preparations (12.1\%), C01E B - other cardiac preparations (9.2\%) and A16A X - various alimentary tract and metabolism products (7.7\%). In a lesser degree, there are represented medications of group $\mathrm{C} 05 \mathrm{CX}$ - other capillary stabilising agents and $A 11 \mathrm{~A} B$ - multivitamins, other combinations, which comprise only $0.3 \%$ from the general assortment of neuroprotective medications introduced in the pharmaceutical market of Ukraine (Table 1) [Information retrieval system "State Register of drugs of Ukraine", Kovalenko and Viktorova, 2009].

We also investigated the correlation of nomenclature of medications of home and foreign production within the limits of each pharmacotherapeutic group of neuroprotective medications (Fig. 2).

\section{Manufacturing firms of neuroprotective medications}

The next stage of the analysis we carried out was the research on suppliers of the neuroprotective action medications in the home pharmaceutical market. It should be noted that currently, basic assortment of the medications in the pharmaceutical market in Ukraine is being formed by means of preparations of foreign manufacture. A part of registered neuroprotective medications of Ukrainian manufacture in relation to imported medications presents $38.8 \%$ (which makes 131 stock keeping unit) against $61.2 \%$.

In the next stage of our research, we performed an analysis of assortment of neuroprotective action medications of foreign pharmaceutical manufacturers (Fig. 3).

\section{Assortment of dosage forms}

In the next stage of our research, we analysed the assortment of medications according to dosage forms. It was established that the investigated preparations are considerably varied by dosage forms. Therefore, in the home pharmaceutical market medications are presented in 11 dosage forms, most of which make up tablets $-51.7 \%$, solutions for injections make up $26.6 \%$ of nomenclatures and capsules $-11.2 \%$. There are also registered solutions for oral use, suspensions for oral use, concentrates for infusions, lyophilisates for injections, nasal drops, powders for oral solutions, solutions for infusions and dragee, which together make up $10.5 \%$ of all dosage forms of neuroprotective medications that are present in the pharmaceutical market in Ukraine (Fig. 4).

\section{Discussion}

The investigation conducted showed that from 25 pharmacotherapeutic groups of medications used for ischaemic stroke treatment, home-manufactured medications make the most part in the group of bioflavonoids (80\%), and in the groups of nicotinic acid and derivatives, xanthine derivatives and vitamin B1 plain, the full assortment of medications is provided (100\%). Among the nomenclature of remedies that are used for dementia, home producers in the Ukrainian pharmaceutical market provide only $7 \%$ of the general assortment of this group. Analysis of the assortment of anti-cholinesterases, other parasympathomimetics, fatty acid derivatives, vitamin B-complex plain, other cardiac combination products, multivitamins, other combinations, other capillary stabilising agents showed that in the nomenclature of the abovementioned pharmacotherapeutic groups, the medications of home manufacture are not presented in the pharmaceutical market of Ukraine.

According to the amount of the preparations presented in the market, Ukraine is in first place among all supplying countries of neuroprotective medications to the home pharmaceutical market. It is determined that the nomenclature of homemanufactured neuroprotective medications is provided by 31 producing firms, among which the leading position by the volume of supply belongs to the pharmaceutical firm "Darnytsia" and JSC "Galychpharm", preparations of each of these firms make $10.7 \%$ of the general assortment of home-produced neuroprotective medications ( 14 items by each firm). In addition, the considerable volume of products to the internal pharmaceutical market comes from the pharmaceutical company "Zdorovie" Ltd - 10\% (13 items), "Farmak" JSC - 9.2\% (12 items), 


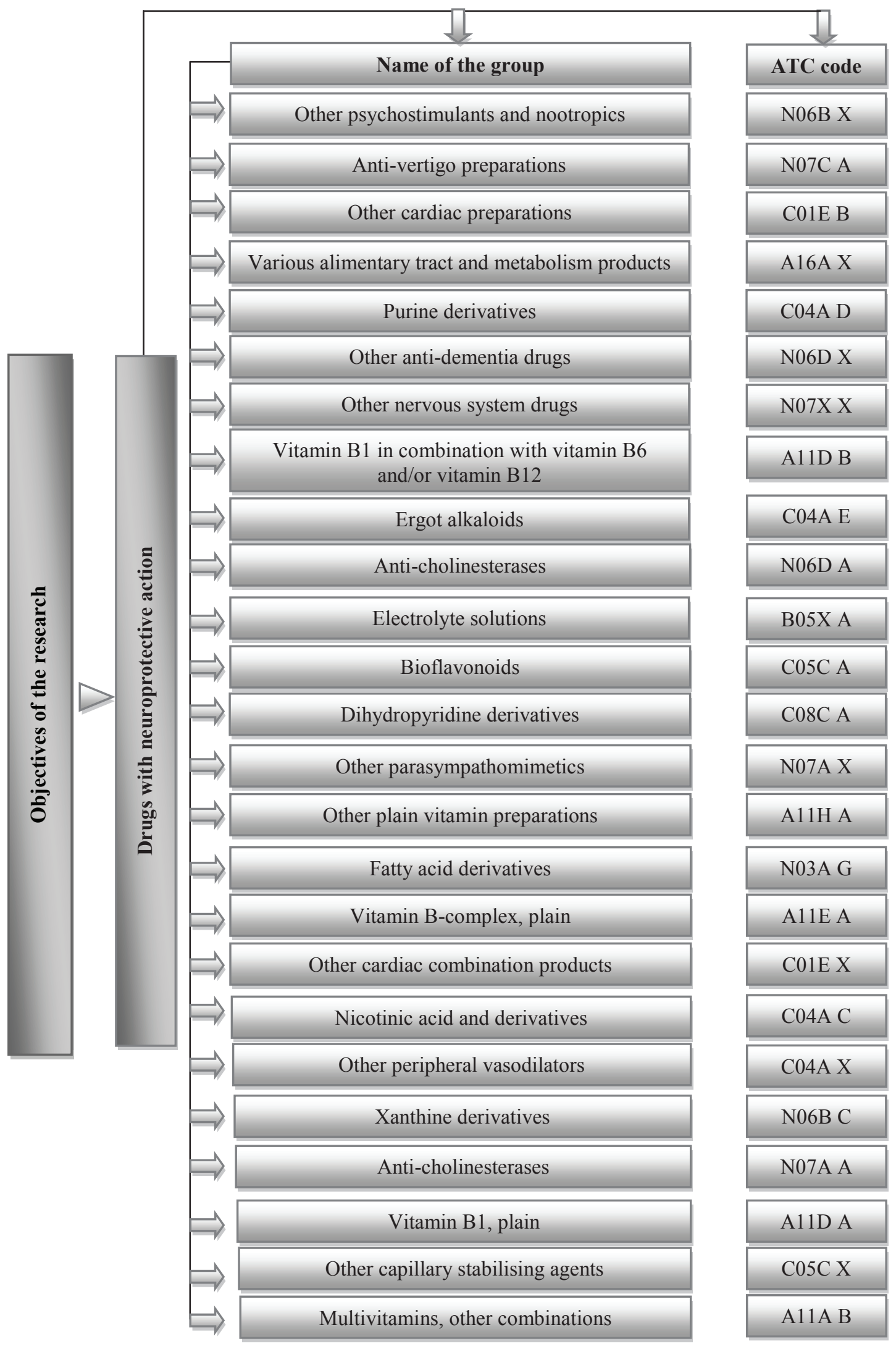

Figure 1. The objectives of the research. 
Acta Fac. Pharm. Univ. Comen. LX, 2013, (1), p. 1-20

MARKETING RESEARCHES OF MARKET ON MEDICATIONS FOR NEUROPROTECTIVE ACTION IN UKRAINE

Table 1. Structure of neuroprotective medications assortment according to ATC classification

\begin{tabular}{|c|c|c|c|}
\hline \multirow[b]{2}{*}{ ATC code } & \multirow[b]{2}{*}{ Name of the group } & \multicolumn{2}{|c|}{ Trade names } \\
\hline & & $\begin{array}{l}\text { Absolute } \\
\text { number }\end{array}$ & $\begin{array}{c}\text { Share in total, } \\
\%\end{array}$ \\
\hline N06B X & Other psychostimulants and nootropics & 108 & 32 \\
\hline N07C A & Anti-vertigo preparations & 41 & 12.1 \\
\hline C01EB & Other cardiac preparations & 31 & 9.2 \\
\hline $\mathrm{A} 16 \mathrm{AX}$ & Various alimentary tract and metabolism products & 26 & 7.7 \\
\hline CO4A D & Purine derivatives & 22 & 6.5 \\
\hline N06D X & Other anti-dementia drugs & 15 & 4.4 \\
\hline N07XX & Other nervous system drugs & 15 & 4.4 \\
\hline A11DB & Vitamin B1 in combination with vitamin $\mathrm{B} 6$ and/or vitamin $\mathrm{B} 12$ & 14 & 4.1 \\
\hline C04A E & Ergot alkaloids & 10 & 3 \\
\hline N06D A & Anti-cholinesterases & 6 & 1.8 \\
\hline B05X A & Electrolyte solutions & 5 & 1.5 \\
\hline $\mathrm{C05CA}$ & Bioflavonoids & 5 & 1.5 \\
\hline C08C A & Dihydropyridine derivatives & 5 & 1.5 \\
\hline N07AX & Other parasympathomimetics & 5 & 1.5 \\
\hline $\mathrm{A} 11 \mathrm{HA}$ & Other plain vitamin preparations & 4 & 1.2 \\
\hline N03A G & Fatty acid derivatives & 4 & 1.2 \\
\hline A11E A & Vitamin B-complex, plain & 3 & 0.9 \\
\hline C01EX & Other cardiac combination products & 3 & 0.9 \\
\hline C04AC & Nicotinic acid and derivatives & 3 & 0.9 \\
\hline C04AX & Other peripheral vasodilators & 3 & 0.9 \\
\hline N06B C & Xanthine derivatives & 3 & 0.9 \\
\hline N07A A & Anti-cholinesterases & 3 & 0.9 \\
\hline A11D A & Vitamin B1, plain & 2 & 0.6 \\
\hline$A 11 A B$ & Multivitamins, other combinations & 1 & 0.3 \\
\hline $\cos C X$ & Other capillary stabilising agents & 1 & 0.3 \\
\hline
\end{tabular}



The share of preparations of Ukrainian manufacture, $\%$

- The share of preparations of foreign manufacture, $\%$

Figure 2. Nomenclature of medications of home and foreign manufacture within the limits of pharmacotherapeutic groups of neuroprotective medications. 


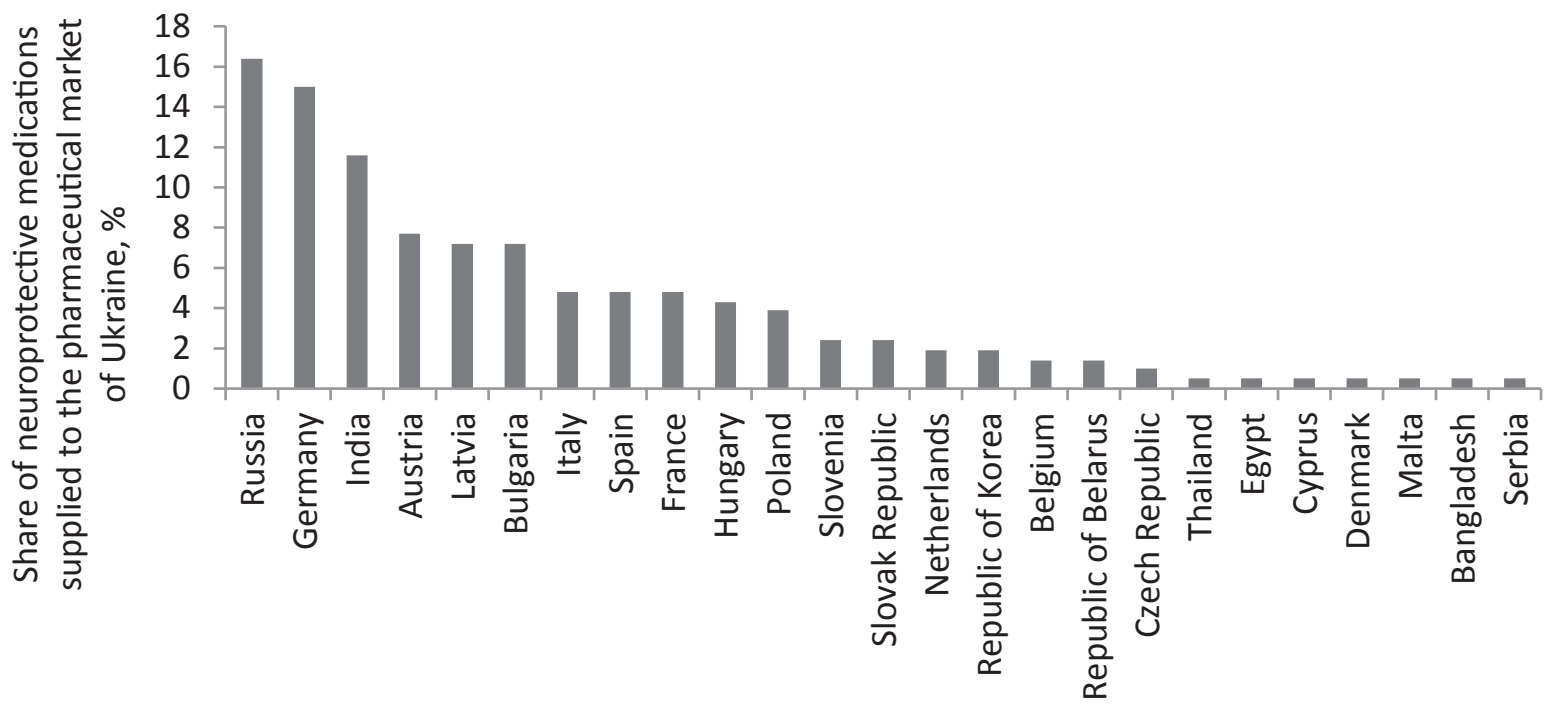

Figure 3. Rating of foreign countries-suppliers of neuroprotective medications in the Ukrainian pharmaceutical market.

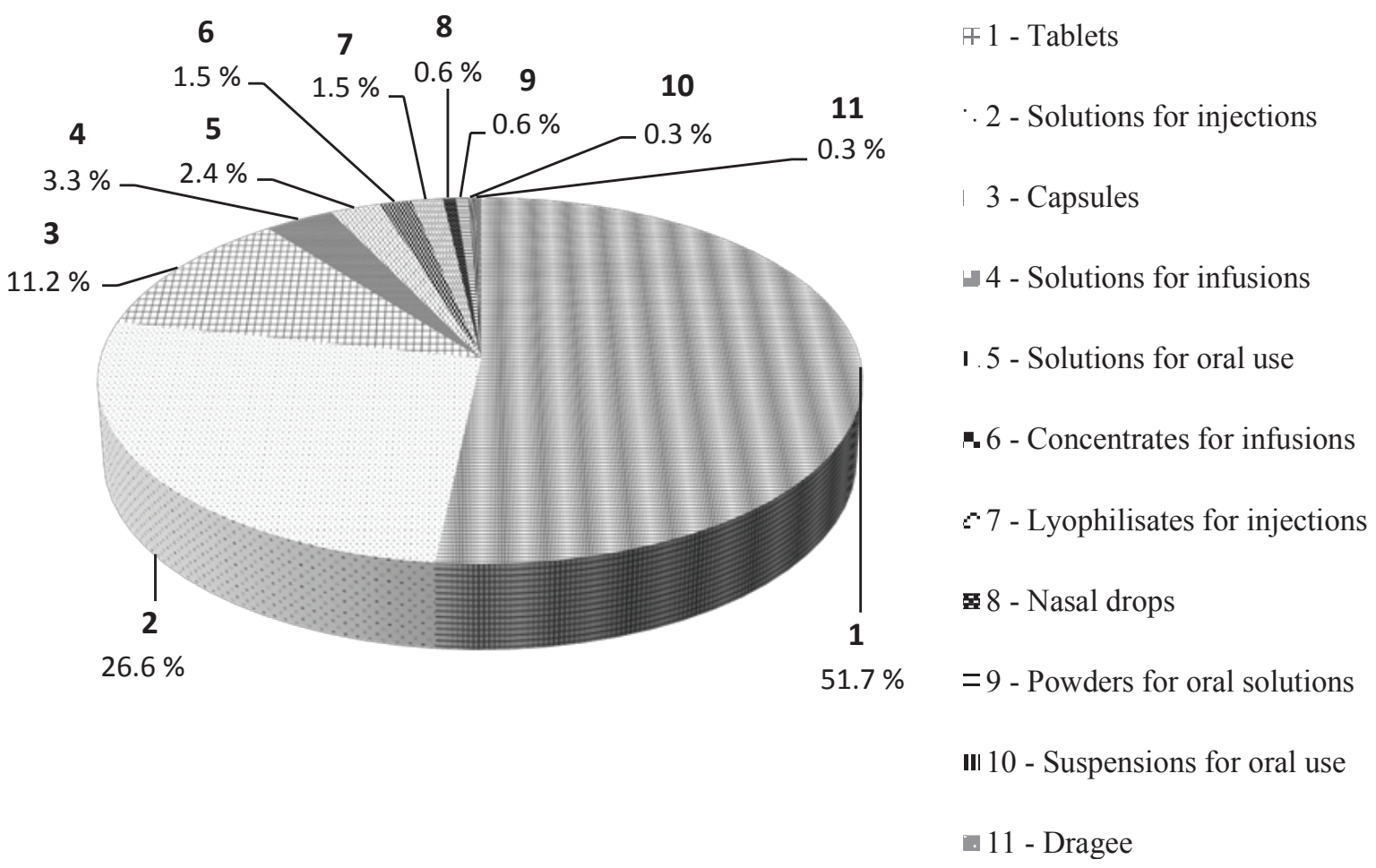

Figure 4. Structure of neuroprotective medications market depending on dosage forms.

PJSC SIC "Borshchahivskiy CPP" - 5.3\% (7 items) and "Pharmex Group" LLC - 5.3\% (7 items). Thus, the given manufacturing firms supply to the internal pharmaceutical market $51.2 \%$ of the general assortment of neuroprotective medications of home manufacture.

The assortment of medications for ischaemic stroke treatment of foreign manufacture is provided by 84 firms-manufacturers from 25 countries of the world, among which the first place belongs to Russia (16.4\% of the assortment of medications of neuroprotective action of foreign manufacture), Germany is the second (15\%) and India is the third (11.6\%). The least amount of stock-keeping units in the pharmaceutical market of Ukraine is presented by Thailand, Egypt, Cyprus, Denmark, Malta, Bangladesh and Serbia, each of which supply $0.5 \%$ of medications of neuroprotective action of foreign manufacture presented in the Ukrainian pharmaceutical market.

According to the results of the research, it was determined that the assortment of foreign neuroprotective medications dif- 
fers in the greater variety of dosage forms in comparison with home medications. Thus, neuroprotective medications of the Ukrainian manufacture are not presented in the pharmaceutical market in the form of suspensions for oral use, nasal drops, powders for oral solution and dragee. This fact points out the perspective and urgent necessity of home manufacturers reorientation on production of medications similar to the imported drugs with high efficiency and ease of application.

\section{Conclusions}

There was an investigation conducted on the assortment of medications for neuroprotective action presented in the pharmaceutical market of Ukraine. According to the data received, it was determined that the home pharmaceutical market mostly presented medications of the groups of other psychostimulants and nootropics, anti-vertigo preparations, other cardiac preparations and various alimentary tract and metabolism products that all together make $61 \%$ of medications for neuroprotective action.

Herewith leading positions in terms of volume supplied belongs to ZAT (Close Joint-Stock Company), the pharmaceutical firms "Darnytsia" and JSC "Galychpharm" and preparations of each of the firms make $10.7 \%$ of general assortment of homeproduced medications.

The rating of 25 foreign countries-suppliers of medications for neuroprotective action to the pharmaceutical market of Ukraine showed that Russia leads first in terms of volume of the presented medications, preparations of which form $16.4 \%$ of the assortment of neuroprotective drugs of foreign production, the second place by the volume of supply belongs to Germany (15\%) and third is India (11.6\%).

The investigation that was conducted allows to specify the basic directions of perfection of the assortment of medications for neuroprotective action for home manufacturing firms. In particular the expansion of the nomenclature of medications, which belong to the following pharmacotherapeutic groups: other anti-dementia drugs, anti-cholinesterases, other parasympathomimetics, fatty acid derivatives, vitamin B complex, plain, other cardiac combination products, multivitamins, other combinations and other capillary stabilising agents.

With regard to dosage forms, it is essential to increase the nomenclature of neuroprotective drugs in the form of suspensions for oral use, nasal drops and powders for oral solution.

\section{REFERENCES}

[1] Lopez AD, Mathers CD, Ezzati M, Jamison DT, Murray CJ. Global and regional burden of disease and risk factors: systematic analysis of population health data. Lancet 2006; 367: 1747-1757.

[2] Marunich VV, Ipatov AV, Korobkin UI, et al. Basic indicators of disability and medical social expert commissions of Ukraine in 2010: analytical and information guide. In: Yemets IM, editor. Dnipropetrovsk: Porogi, 2011: 135.

[3] Anishchenko OJ, editor. Annual report on the State of Health of Ukraine and sanitary epidemiological situation in 2010. Ministry of Health of Ukraine, Kyiv, 2011: 461.

[4] Brainin M, Bornstein N, Boysen G, Demarin V. Acute neurological stroke care in Europe: results of the European Stroke Care Inventory. Eur J Neurol 2000; 7: 5-10.

[5] Mureshanu DF. Integrated approach to neuroprotection and neuroplasticity in stroke therapy. Int Neurol J 2007; 6 (16): 63-66.

[6] Alonso de Lecinana M, Diez-Tejedor E, Gutierrez M, Guerrero S, Carceller F, Roda JM. New goals in ischemic stroke therapy: the experimental approach - harmonizing science with practice. Cerebrovasc Dis 2005; 20 (Suppl 2): 159-168.

[7] Information retrieval system "State Register of drugs of Ukraine". http://www.drlz.kiev.ua. Accessed January 10, 2013.

[8] Kovalenko VN, Viktorova AP. Compendium 2009 - drugs. Kiev: Morion, 2009: 2270.
Alla Anatoliivna Kotvitska, PhD, Doctor of Pharmacy, professor Department of Social Pharmacy National University of Pharmacy Blucher 4, 61168 Kharkiv, Ukraine socpharm@ukr.net Tel.: +38-(0572)-67-91-81
Inna Olexandrivna Lobova

Department of Social Pharmacy

National University of Pharmacy

Blucher 4, 61168 Kharkiv, Ukraine inna.lobova@mail.ru Tel.: +38-(0572)-67-91-81 